\title{
Novel and Functional DNA Sequence Variants within the GATA6 Gene Promoter in Ventricular Septal Defects
}

\author{
Chunyu Li ${ }^{1, \dagger}$, Xianke Li ${ }^{2, \dagger}$, Shuchao Pang ${ }^{3, \dagger}$, Wei Chen ${ }^{4}$, Xianyun Qin ${ }^{3}$, Wenhui Huang ${ }^{3}$, \\ Changqing Zeng ${ }^{4, *}$ and Bo Yan ${ }^{3, *}$
}

1 Division of Electrocardiogram, Jining Medical University Affiliated Hospital, Jining Medical University, Jining 272029, China; E-Mail: 1lichunyu@163.com

2 Division of Anesthesia, Jining First People's Hospital, Jining 272011, China; E-Mail: 13963722217@163.com

3 Shandong Provincial Key Laboratory of Cardiac Disease Diagnosis and Treatment, Jining Medical University Affiliated Hospital, Jining Medical University, Jining 272029, China; E-Mails: tonyp0720@126.com (S.P.); qinxianyun@126.com (X.Q.); huangwenhui1986@163.com (W.H.)

4 Laboratory of Genome Variation and Precision Biomedicine, Beijing Institute of Genomics, Chinese Academy of Sciences, Beijing 100101, China; E-Mail: chenw@big.ac.cn

$\dagger$ These authors contributed equally to the work.

* Authors to whom correspondence should be addressed;

E-Mails: czeng@big.ac.cn (C.Z.); yanbmd@gmail.com (B.Y.);

Tel.: +86-10-8409-7818 (C.Z.); +86-537-290-3579 (B.Y.);

Fax: +86-10-8409-7706 (C.Z.); +86-537-221-3030 (B.Y.).

Received: 29 April 2014; in revised form: 16 June 2014 / Accepted: 8 July 2014 /

Published: 17 July 2014

\begin{abstract}
Congenital heart disease (CHD) is the most common birth defect in humans. Genetic causes and underlying molecular mechanisms for isolated CHD remain largely unknown. Studies have demonstrated that GATA transcription factor 6 (GATAO) plays an essential role in the heart development. Mutations in GATA6 gene have been associated with diverse types of CHD. As GATA6 functions in a dosage-dependent manner, we speculated that changed GATA6 levels, resulting from DNA sequence variants (DSVs) within the gene regulatory regions, may mediate the CHD development. In the present study, GATA6 gene promoter was genetically and functionally analyzed in large groups of patients with ventricular septal defect (VSD) $(n=359)$ and ethnic-matched healthy controls
\end{abstract}


$(n=365)$. In total, 11 DSVs, including four SNPs, were identified in VSD patients and controls. Two novel and heterozygous DSVs, g.22169190A $>$ T and g.22169311C $>$ G, were identified in two VSD patients, but in none of controls. In cultured cardiomyocytes, the activities of the GATA6 gene promoter were significantly reduced by the DSVs g.22169190A $>$ T and g.22169311C $>$ G. Therefore, our findings suggested that the DSVs within the GATA6 gene promoter identified in VSD patients may change GATA6 levels, contributing to the VSD development as a risk factor.

Keywords: congenital heart disease; ventricular septal defect; GATA6; promoter; DNA sequence variants

\section{Introduction}

Congenital heart disease (CHD) is the most common human birth defects affecting $1 \%-2 \%$ of live birth [1]. In the past two decades, genetic studies and animal experiments have revealed a number of CHD-associated genes, including GATA factor 4 (GATA4), T-box transcription factor 5 (TBX5) and NK2 transcription factor related-locus $5(N K X 2-5)$ [2,3]. However, genetic causes and underlying molecular mechanisms for isolated CHD, which account for a majority of CHD cases, remain largely unknown. GATA6 is a member of GATA transcription factor family containing a highly conserved DNA-binding domain. During the embryonic development, GATA factors regulate the cell differentiation, proliferation and survival. GATA1, GATA2 and GATA3 genes are expressed in hematopoietic stem cells and related derivatives. GATA4, GATA5 and GATA6 genes are expressed in various tissues derived from mesoderm and endoderm. In the developing heart, GATA4, GATA5 and GATA6 genes are expressed in a partial overlapping pattern [4-6].

GATA6 gene is expressed in developing heart and continues to be expressed in the adult cardiomyocytes in human and experimental animals [7,8]. In mouse embryos, GATA6 gene is expressed in the precardiac mesoderm, heart tube, atria and ventricles [7,9]. GATA6 plays an important role in endocardial cushion formation and outflow tract morphogenesis [10]. Targeted disruption of GATA6 gene in mice leads to embryonic lethality with defective endodermal differentiation [11]. Mice with heterozygous deletion of GATA6 gene develop normally [12]. Cardiomyocyte-specific deletion and over-expression experiments have indicated that GATA6 gene is required for cardiac hypertrophic response and differentiated gene expression in myocytes [13]. Tissue-specific inactivation of GATA6 gene in vascular smooth muscles or neural crest causes cardiovascular defects, including interrupted aortic arch and persistent truncus arteriosus [14]. In addition, GATA6, like GATA4, can direct the efficient generation of cardiomyocytes from embryonic stem cells [15]. Therefore, GATA6 is a critical regulator in the heart development.

GATA6 gene mutations have been reported in familial and isolated CHD patients in different ethnic populations, including atrial septal defect, atrioventricular septal defect, persistent truncus arteriosus, tetralogy of Fallot and ventricular septal defect (VSD) [16-25]. Mutations in GATA6 gene include missense mutations, deletions and copy number variants. GATA6 gene mutations have also been found in patients with diabetes and pancreatic agenesis [26-28]. To date, GATA6 gene mutations found in 
CHD patients are located in the coding regions and splicing sites, regulatory regions of GATA6 gene have not been studied and reported. GATA6 has been demonstrated to act in a dosage-dependent manner in the heart [12,29]. Thus, we speculated that the DNA sequence variants (DSVs) within the GATA6 gene regulatory regions may alter GATA6 levels and mediate the CHD development. In the present study, promoter region of the human GATA6 gene was genetically and functionally analyzed in large groups of VSD patients and healthy controls.

\section{Results and Discussion}

\subsection{DNA Sequence Variants (DSVs) Identified in Ventricular Septal Defect (VSD) Patients and Controls}

The GATA6 gene promoters were bi-directionally sequenced in VSD patients $(n=359)$ and healthy controls $(n=365)$. In total, 11 DSVs, including four single-nucleotide polymorphisms (SNPs) were identified, distributions of which were summarized in Table 1. The locations of the DSVs were indicated in Figure 1A. Chromatograms of the novel DSVs were shown in Figure 1B. Two novel heterozygous DSVs, g.22169190A $>$ T and g.22169311C $>$ G, were identified in two VSD patients, but in none of controls. The DSV g.22169190A $>$ T was found in a two-year-old boy with a membranous VSD and the DSV g.22169311C $>\mathrm{G}$ in a 5-year-old boy with a muscular VSD. Four novel and heterozygous DSVs, g.22168974G $>$ A, g.22169233C $>$ A, g.22169278G $>$ A and g.22169391-del, were only found in three controls. The deletion DSV, g.22169391-del, was confirmed by subcloning the DNA fragment into an expression vector and direct sequencing. One novel and heterozygous DSV, g.22169345C $>$ T, and four SNPs, g.22168449A $>$ G (rs189133474), g.22168944G $>$ A (rs144923558), g.22169265G $>$ A (rs146748749) and g.22169346C $>$ G (rs 139399350), were identified in both VSD patients and controls with similar frequencies. In addition, the SNPs, g.22168944G $>$ A (rs144923558) and g.22169265G $>$ A (rs146748749), were in complete linkage disequilibrium $\left(D^{\prime}=1, r^{2}=1\right)$ in this study population.

Table 1. GATA transcription factor 6 (GATA6) gene promoter DNA sequence variants (DSVs) in ventricular septal defect (VSD) patients and controls.

\begin{tabular}{|c|c|c|c|c|c|}
\hline DSVs & Genotype & Location $^{\text {a }}$ & Controls $(n=365)$ & VSD $(n=359)$ & $p$ Value \\
\hline g.22168449A >G (rs189133474) & $\mathrm{AG}$ & $-994 b p$ & 10 & 6 & 0.329 \\
\hline \multirow{3}{*}{ g.22168944G $>$ A (rs144923558) } & GG & -499 bp & 347 & 333 & 0.212 \\
\hline & GA & & 18 & 24 & \\
\hline & AA & & 0 & 2 & \\
\hline g.22168974G $>A$ & GA & $-469 \mathrm{bp}$ & 1 & 0 & - \\
\hline g. $22169190 \mathrm{~A}>\mathrm{T}$ & AT & $-253 b p$ & 0 & 1 & - \\
\hline g. $22169233 \mathrm{C}>\mathrm{A}$ & $\mathrm{CA}$ & $-210 b p$ & 1 & 0 & - \\
\hline \multirow{3}{*}{ g.22169265G $>$ A (rs146748749) } & GG & $-178 b p$ & 347 & 333 & 0.212 \\
\hline & GA & & 18 & 24 & \\
\hline & AA & & 0 & 2 & \\
\hline g.22169278G $>A$ & GA & $-165 \mathrm{bp}$ & 1 & 0 & - \\
\hline g. $22169311 \mathrm{C}>\mathrm{G}$ & CG & $-132 b p$ & 0 & 1 & - \\
\hline g. $22169345 \mathrm{C}>\mathrm{T}$ & $\mathrm{CT}$ & $-96 b p$ & 5 & 7 & 0.541 \\
\hline \multirow{3}{*}{ g.22169346C $>\mathrm{G}(\mathrm{rs} 139399350)$} & $\mathrm{CC}$ & $-97 \mathrm{bp}$ & 316 & 313 & 0.330 \\
\hline & CG & & 48 & 43 & \\
\hline & GG & & 1 & 3 & \\
\hline g.22169391-del & $\begin{array}{c}\mathrm{CCTCCT} \\
\mathrm{CC} /-\end{array}$ & $-45-52 \mathrm{bp}$ & 1 & 0 & - \\
\hline
\end{tabular}

a DSVs were located upstream to the transcription start site (22169443, NC_000018.10); -, not compared. 
Figure 1. The DSVs within the GATA6 gene promoter identified in VSD patients and controls. (A) Schematic representation of the identified GATA6 gene DSVs. The DSVs were named according to their locations in the GATA6 genomic sequences (NCBI: NC_000018.10). The transcription starts at 22169443 in the first exon that is untranslated; (B) Chromatograms of the seven novel and heterozygous DSVs. Sequencing orientations are indicated as forward or reverse. Top panels show wild type and bottom panels heterozygous DSVs. DSVs are marked with arrows and deletion is underlined. The heterozygous deletion DSV, g.22169391-del, was confirmed by subcloning the DNA fragments into expression vector pGL3-basic and directly sequenced.

A.

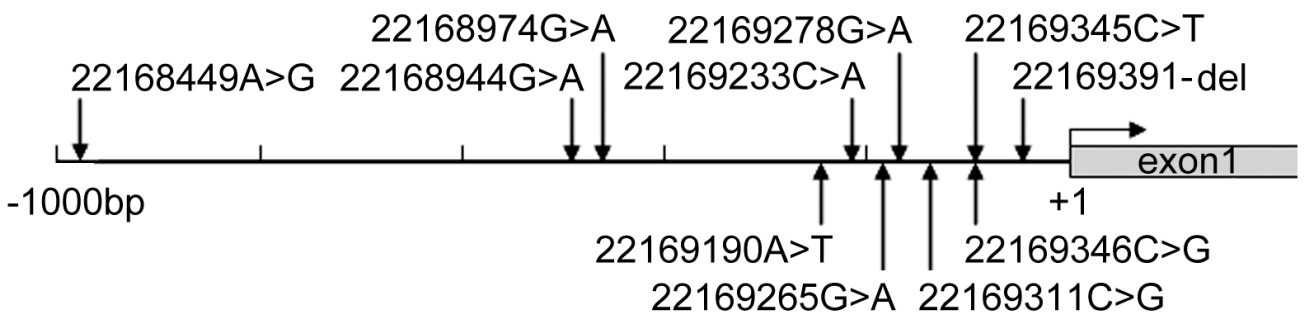

B.
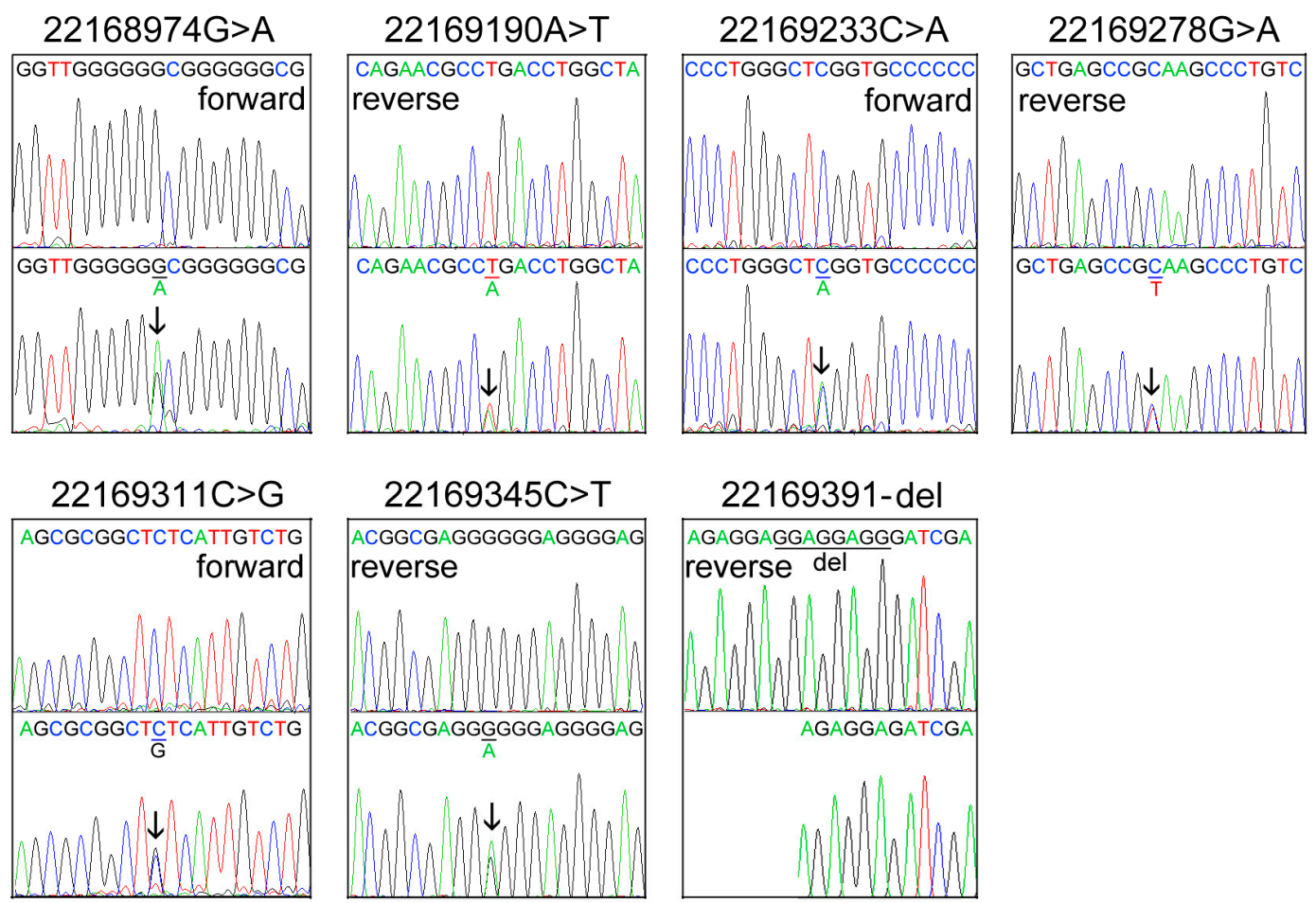

\subsection{Functional Analysis of the DSVS}

The two novel DSVs identified in VSD patients, g.22169190A $>$ T and g.22169311C $>$ G, were analyzed with TFSEARCH program (http://www.cbrc.jp/research/db/TFSEARCH.html) [30]. The results suggested that the DSV g.22169190A $>$ T may abolish a putative binding site for retinoid-related orphan receptor alpha 1 . The DSV g.22169311C $>$ G did not affect binding site for known putative transcription factors. To examine their transcriptional activities, expression constructs containing 
wild type (pGL3-WT) and variant GATA6 gene promoters (pGL3-22168449G, pGL3-22168944A, pGL3-22168974A, pGL3-22169190T and pGL3-22169311G.) were generated. The constructs were transfected into $\mathrm{H} 9 \mathrm{c} 2$ cells and dual-luciferase activities were measured. The results showed that the DSVs, g.22169190A $>$ T and g.22169311C $>$ G, significantly reduced the transcriptional activities of the GATA6 gene promoter (Figure 2). In contrast, the DSV, g.22168974G $>$ A, and two SNPs, g.22168449A $>$ G (rs189133474) and g.22168944G $>$ A (rs144923558), did not significantly change the GATA6 gene promoter activity.

Figure 2. Relative transcriptional activities of the wild type and variant GATA6 gene promoters. GATA6 gene expression constructs were transfected into H9c2 cells and dual-luciferase activities were measured. The transcriptional activity of wild type GATA6 gene promoter was designated as $100 \%$. The data were represented as mean \pm SEM from three independent transfection experiments, in triplicate. Lanes 1, pGL3-basic, a negative control; 2, WT, wild type; 3, pGL3-22168449G; 4, pGL3-22168944A; 5, pGL3-22168974A; 6, pGL3-22169190A>T; 7, pGL3-22169311G. *, $p<0.001$, compared to pGL3-WT.

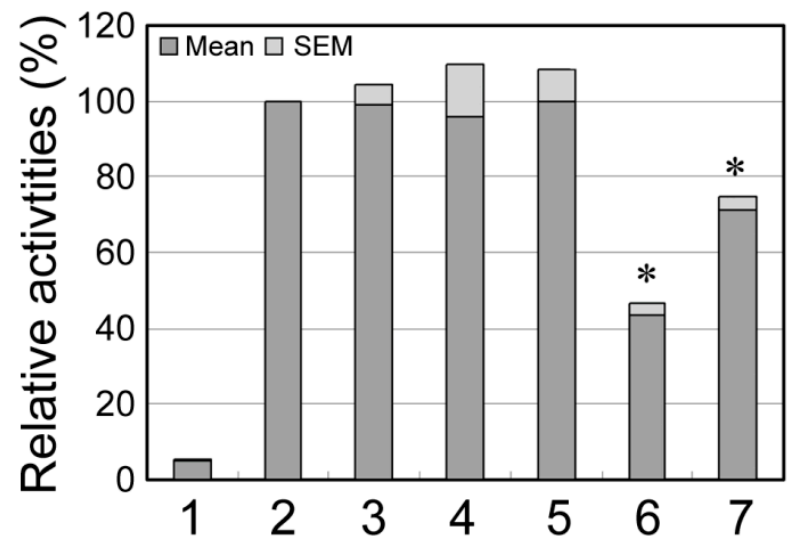

\subsection{Discussion}

Misregulation of gene expression programs has been implicated in a broad range of human diseases, including cancer, inflammation, diabetes and cardiovascular diseases [31]. A set of de novo mutations in histone modification-related genes, which affect levels of transcriptional outputs, has been found in CHD patients [32]. Two loci have been identified in patients with secundum atrial septal defect with genome-wide association studies [33]. In the present study, we identified two novel heterozygous DSVs within the GATA6 gene promoter in two VSD patients, which were found in none of controls. In cultured cardiomyocytes, these DSVs significantly reduced the transcriptional activities of the GATA6 gene promoter. Therefore, these GATA6 gene DSVs may mediate the DSV development as a risk factor.

Human GATA6 gene has been localized to chromosome 18q11.1-q11.2 [8]. In human, GATA6 is mainly expressed in fetal heart and lung. GATA6 is also expressed in adult heart, pancreas, ovary, lung, liver, central nervous system, adrenal and vascular smooth muscle cells $[8,34,35]$. Although the human GATA6 gene promoter has not been characterized, the $5^{\prime}$ upstream region $(\sim 1.2 \mathrm{~kb})$ of the mouse GATA6 gene has been shown to be necessary for its heart-specific expression [9,36]. A mouse GATA6 cardiac enhancer has been identified, which is directly activated by $N K X 2-5$ [37]. Reduced or elevated GATA6 gene expression has been reported in patients with neonatal lung diseases, pulmonary arterial 
hypertension, pancreatic carcinoma, malignant astrocytoma and polycystic ovary syndrome [38-42]. The two GATA6 gene DSVs identified in this study, located at -132 and -253 bp upstream to the transcription start site, may change GATA6 levels during the heart development.

In the heart development, many networks of cardiac transcription factors, cofactors and chromatin regulators are strictly interacted and regulated [43-46]. Animal studies have demonstrated that GATA6 regulates and interacts with a number of critical transcription factors and structural molecules. GATA6 interacts with GATA4 to synergistically regulate atrial natriuretic factor $(A N F)$ and B-type natriuretic peptide $(B N P)$ gene expression by binding to their promoters [47]. Loss of both Gata4 and Gata6 leads to acardia in mice [48]. GATA6 interacts with GATA5 in endocardial cushion formation and outflow tract development. Compound loss of a GATA5 and a GATA6 allele leads to double outlet right ventricle and VSD [10]. GATA6 and TBX5 synergistically activate $A N F$ gene in the developing heart [49]. $N K X 2-5$ gene expression is regulated by a number of cardiac-specific enhancers containing GATA binding sites [50,51]. Heterozygous loss of GATA6 gene result in reduced expression of NKX2-5 gene [10]. In addition, Hey basic helix-loop-helix transcription factor 2 (Hey2), a downstream effector of Notch signaling, binds to GATA6 and directly represses $A N F$ gene expression [52]. Mice lacking Hey2 develop VSD and cardiomyopathy [53]. Therefore, altered levels of GATA6 may contribute to the CHD development by interfere with cardiac gene regulatory networks.

\section{Materials and Methods}

\subsection{Patients and Controls}

All VSD patients ( $n=359$, male 184, female 175, age range from 3 months to 42 years, median age 4.17 years) were recruited from Division of Cardiac Surgery, Jining Medical University Affiliated Hospital, Jining Medical University, Jining, Shandong, China. The VSD patients were diagnosed with three-dimensional echocardiography and further confirmed with cardiac surgery or cardiac catheterization. In this cohort of VSD patients, none had familial CHD history. Ethnic-matched healthy controls ( $n=365$, male 304 , female 61 , age range from one month to 39 years, median age 3.67 years) were from the same hospital. This study (NSFC 81370271, 2013) was approved by the Human Research Ethics Committee of Jining Medical University Affiliated Hospital. Informed consents were obtained from patients and guardians.

\subsection{Sequence Analysis}

Leukocytes were isolated from vein blood. Genomic DNAs were extracted with QIAamp DNA mini kit (QIAGEN, Valencia, CA, USA). GATA6 PCR primers were designed based on genomic sequence of the human GATA6 gene (NCBI: NC_000018.10). GATA6 gene promoter of $1315 \mathrm{bp}$ (from -1246 to $+69 \mathrm{bp}$ to the transcription start site) was sequenced. Two overlapping DNA fragments, 695 bp $(-1246 \sim-551 \mathrm{bp})$ and $663 \mathrm{bp}(-594 \mathrm{p} \sim+69 \mathrm{bp})$, were generated with PCR. The sequences and locations of the PCR primers were shown in Table 2. The PCR products were bi-directionally sequenced with 3500 Genetic Analyzer (Applied Biosystems, Foster City, CA, USA). DNA sequences were aligned and compared with the wild type sequence of the GATA6 gene promoter. 
Table 2. PCR primers for the human GATA6 gene promoter ${ }^{\mathrm{a}}$.

\begin{tabular}{cccc}
\hline Primers & Sequences & Location & Products \\
\hline Sequencing & & & \\
GATA6-F1 & 5'-ACCAGAGCCTAAACGCTTTC-3' & 22168197 & $695 \mathrm{bp}$ \\
GATA6-R1 & 5'-ACCCTATCTCGGGATGCTAC-3' & 22168891 & \\
GATA6-F2 & 5'-CCGAAACCACCACGACCTGAG-3' & 22168849 & $663 \mathrm{bp}$ \\
GATA6-R2 & 5'-TGGGCTCCTGATTGGACTCACC-3' & 22169511 & \\
\hline Functioning & & & \\
GATA6-F & 5'-(KpnI)-ACGCCTCTTGTCCTAAAGTCTC-3' & 22168318 & $1173 \mathrm{bp}$ \\
GATA6-R & 5'-(HindIII)-CGAGCCCTAAACAAACAGC-3' & 22169490 & \\
\hline aCR primers were designed based on the genomic DNA sequence & of the human GATA6 gene. \\
(NC_000018.10). The transcription start site (+1) is at position of 22169443. &
\end{tabular}

\subsection{Functional Analysis}

The DNA fragments of wild type and variant GATA6 gene promoters (1173 bp, from -1125 to $+48 \mathrm{bp}$ ) were generated by PCR. As shown in Table 1, a KpnI site was added to the GATA6 forward primer and a HindIII site to the GATA6 reverse primer. Expression constructs were generated by subcloning PCR products into KpnI and HindIII sites of a reporter vector-pGL3-basic, expressing luciferase gene. To examine the activities of the GATA6 gene promoters, designated expression constructs $(2.0 \mu \mathrm{g})$ were transiently transfected into rat cardiomyocyte cells $(\mathrm{H} 9 \mathrm{c} 2)$ in 6-well plates. The transfected cells were collected $48 \mathrm{~h}$ posttransfection. Expression construct expressing renilla luciferase gene $(p R L-T K)$ (40 ng) was used as an internal control. Empty vector pGL3-basic was used as a negative control. Luciferases activities were measured using dual-luciferase reporter assay system on a Glomax 20/20 luminometer (Promega, Madison, WI, USA). The transcriptional activities of the gene promoter were represented as ratios of luciferase over renilla luciferase activities. All the experiments were repeated at least three times independently, in triplicate.

\subsection{Statistical Analysis}

Quantitative data were represented as mean \pm SEM and compared by a standard Student's $t$-test. Frequencies of the DSVs within the GATA6 gene promoter in VSD patients and controls were compared with SPSS v13.0 (SPSS, Chicago, IL, USA). A $p<0.05$ was considered as statistically significant.

\section{Conclusions}

In conclusion, two novel and heterozygous DSVs within the GATA6 gene promoter were identified in VSD patients, which have transcriptional activities in cultured cardiomycytes. The findings suggested that these GATA6 DSVs may be involved in VSD formation by changing GATA6 levels as a risk factor. As morbidity and mortality in adult CHD patients are significantly higher than general populations, likely due to genetic defects [54,55], genetic studies may provide insight into designing novel therapies for adult CHD patients. 


\section{Acknowledgments}

This study was supported by National Natural Science Foundation of China (81370271), 973 Project (2010CB52950) and Shandong Provincial Natural Science Foundation (ZR2010HM111).

\section{Author Contributions}

C. Li, X. Li, S. Pang, W. Chen, X. Qin and W. Huang contributed to the laboratory work and data analyses; C. Zeng and B. Yan designed the study and wrote the manuscript.

\section{Conflicts of Interest}

The authors declare no conflict of interest.

\section{References}

1. Hoffman, J.I.; Kaplan, S. The incidence of congenital heart disease. J. Am. Coll. Cardiol. 2002, 39, 1890-1900.

2. Bruneau, B.G. The developmental genetics of congenital heart disease. Nature 2008, 451, 943-948.

3. Kathiresan, S.; Srivastava, D. Genetics of human cardiovascular disease. Cell 2012, 148, 1242-1257.

4. Burch, J.B. Regulation of GATA gene expression during vertebrate development. Semin. Cell Dev. Biol. 2005, 16, 71-81.

5. Peterkin, T.; Gibson, A.; Loose, M.; Patient, R. The roles of GATA4, GATA5 and GATA6 in vertebrate heart development. Semin. Cell Dev. Biol. 2005, 16, 83-94.

6. Pikkarainen, S.; Tokola, H.; Kerkelä, R.; Ruskoaho, H. GATA transcription factors in the developing and adult heart. Cardiovasc. Res. 2004, 63, 196-207.

7. Morrisey, E.E.; Ip, H.S.; Lu, M.M.; Parmacek, M.S. GATA6: A zinc finger transcription factor that is expressed in multiple cell lineages derived from lateral mesoderm. Dev. Biol. 1996, 177, 309-322.

8. Suzuki, E.; Evans, T.; Lowry, J.; Truong, L.; Bell, D.W.; Testa, J.R.; Walsh, K. The human GATA-6 gene: Structure, chromosomal location, and regulation of expression by tissue-specific and mitogen-responsive signals. Genomics 1996, 38, 283-290.

9. Brewer, A.; Gove, C.; Davies, A.; McNulty, C.; Barrow, D.; Koutsourakis, M.; Farzaneh, F.; Pizzey, J.; Bomford, A.; Patient, R. The human and mouse GATA6 genes utilize two promoters and two initiation codons. J. Biol. Chem. 1999, 274, 38004-38016.

10. Laforest, B.; Nemer, M. GATA5 interacts with GATA4 and GATA6 in outflow tract development. Dev. Biol. 2011, 358, 368-378.

11. Morrisey, E.E.; Tang, Z.; Sigrist, K.; Lu, M.M.; Jiang, F.; Ip, H.S.; Parmacek, M.S. GATA6 regulates HNF4 and is required for differentiation of visceral endoderm in the mouse embryo. Genes Dev. 1998, 12, 3579-3590.

12. Xin, M.; Davis, C.A.; Molkentin, J.D.; Lien, C.L.; Duncan, S.A.; Richardson, J.A.; Olson, E.N. A threshold of GATA4 and GATA6 expression is required for cardiovascular development. Proc. Nat. Acad. Sci. USA 2006, 103, 11189-11194. 
13. Van Berlo, J.H.; Elrod, J.W.; van den Hoogenhof, M.M.; York, A.J.; Aronow, B.J.; Duncan, S.A.; Molkentin, J.D. The transcription factor GATA6 regulates pathological cardiac hypertrophy. Circ. Res. 2010, 107, 1032-1040.

14. Lepore, J.J.; Mericko, P.A.; Cheng, L.; Lu, M.M.; Morrisey, E.E.; Parmacek, M.S. GATA-6 regulates semaphorin $3 \mathrm{C}$ and is required in cardiac neural crest for cardiovascular morphogenesis. J. Clin. Investig. 2006, 116, 929-939.

15. Turbendian, H.K.; Gordillo, M.; Tsai, S.Y.; Lu, J.; Kang, G.; Liu, T.C.; Tang, A.; Liu, S.; Fishman, G.I.; Evans, T. GATA factors efficiently direct cardiac fate from embryonic stem cells. Development 2013, 140, 1639-1644.

16. Huang, R.T.; Xue, S.; Xu, Y.J.; Yang, Y.Q. Somatic mutations in the GATA6 gene underlie sporadic tetralogy of Fallot. Int. J. Mol. Med. 2013, 31, 51-58.

17. Kodo, K.; Nishizawa, T.; Furutani, M.; Arai, S.; Yamamura, E.; Joo, K.; Takahashi, T.; Matsuoka, R.; Yamagishi, H. GATA6 mutations cause human cardiac outflow tract defects by disrupting semaphorin-plexin signaling. Proc. Nat. Acad. Sci. USA 2009, 106, 13933-13938.

18. Kodo, K.; Nishizawa, T.; Furutani, M.; Arai, S.; Ishihara, K.; Oda, M.; Makino, S.; Fukuda, K.; Takahashi, T.; Matsuoka, R.; et al. Genetic analysis of essential cardiac transcription factors in 256 patients with non-syndromic congenital heart defects. Circ. J. 2012, 76, 1703-1711.

19. Lin, X.; Huo, Z.; Liu, X.; Zhang, Y.; Li, L.; Zhao, H.; Yan, B.; Liu, Y.; Yang, Y.; Chen, Y.H. A novel GATA6 mutation in patients with tetralogy of Fallot or atrial septal defect. J. Hum. Genet. 2010, 55, 662-667.

20. Maitra, M.; Koenig, S.N.; Srivastava, D.; Garg, V. Identification of GATA6 sequence variants in patients with congenital heart defects. Pediat. Res. 2010, 68, 281-285.

21. Suzuki, S.; Nakao, A.; Sarhat, A.R.; Furuya, A.; Matsuo, K.; Tanahashi, Y.; Kajino, H.; Azuma, H. A case of pancreatic agenesis and congenital heart defects with a novel GATA6 nonsense mutation: Evidence of haploinsufficiency due to nonsense-mediated mRNA decay. Am. J. Med. Genet. A 2014, 164A, 476-479.

22. Tomita-Mitchell, A.; Mahnke, D.K.; Struble, C.A.; Tuffnell, M.E.; Stamm, K.D.; Hidestrand, M.; Harris, S.E.; Goetsch, M.A.; Simpson, P.M.; Bick, D.P.; et al. Human gene copy number spectra analysis in congenital heart malformations. Physiol. Genomics 2012, 44, 518-541.

23. Wang, J.; Luo, X.J.; Xin, Y.F.; Liu, Y.; Liu, Z.M.; Wang, Q.; Li, R.G.; Fang, W.Y.; Wang, X.Z.; Yang, Y.Q. Novel GATA6 mutations associated with congenital ventricular septal defect or tetralogy of fallot. DNA Cell Biol. 2012, 31, 1610-1617.

24. Yu, L.; Bennett, J.T.; Wynn, J.; Carvill, G.L.; Cheung, Y.H.; Shen, Y.; Mychaliska, G.B.; Azarow, K.S.; Crombleholme, T.M.; Chung, D.H.; et al. Whole exome sequencing identifies de novo mutations in GATA6 associated with congenital diaphragmatic hernia. J. Med. Genet. 2014, 51, 197-202.

25. Zheng, G.F.; Wei, D.; Zhao, H.; Zhou, N.; Yang, Y.Q.; Liu, X.Y. A novel GATA6 mutation associated with congenital ventricular septal defect. Int. J. Mol. Med. 2012, 29, 1065-1071.

26. Allen, H.L.; Flanagan, S.E.; Shaw-Smith, C.; de Franco, E.; Akerman, I.; Caswell, R.; International Pancreatic Agenesis Consortium; Ferrer, J.; Hattersley, A.T.; Ellard, S. GATA6 haploinsufficiency causes pancreatic agenesis in humans. Nat. Genet. 2011, 44, 20-22. 
27. De Franco, E.; Shaw-Smith, C.; Flanagan, S.E.; Shepherd, M.H.; International NDM Consortium; Hattersley, A.T.; Ellard, S. GATA6 mutations cause a broad phenotypic spectrum of diabetes from pancreatic agenesis to adult-onset diabetes without exocrine insufficiency. Diabetes 2013, 62, 993-997.

28. Yorifuji, T.; Kawakita, R.; Hosokawa, Y.; Fujimaru, R.; Yamaguchi, E.; Tamagawa, N. Dominantly inherited diabetes mellitus caused by GATA6 haploinsufficiency: Variable intrafamilial presentation. J. Med. Genet. 2012, 49, 642-643.

29. Van Berlo, J.H.; Aronow, B.J.; Molkentin, J.D. Parsing the roles of the transcription factors GATA4 and GATA6 in the adult cardiac hypertrophic response. PLoS One 2013, 8, e84591.

30. Heinemeyer, T.; Wingender, E.; Reuter, I.; Hermjakob, H.; Kel, A.E.; Kel, O.V.; Ignatieva, E.V.; Ananko, E.A.; Podkolodnaya, O.A.; Kolpakov, F.A.; et al. Databases on Transcriptional Regulation: TRANSFAC, TRRD, and COMPEL. Nucleic Acids Res. 1998, 26, 364-370.

31. Lee, T.I.; Young, R.A. Transcriptional regulation and its misregulation in disease. Cell 2013, 152, 1237-1251.

32. Zaidi, S.; Choi, M.; Wakimoto, H.; Ma, L.; Jiang, J.; Overton, J.D.; Romano-Adesman, A.; Bjornson, R.D.; Breitbart, R.E.; Brown, K.K.; et al. De novo mutations in histone-modifying genes in congenital heart disease. Nature 2013, 498, 220-223.

33. Cordell, H.J.; Bentham, J.; Topf, A.; Zelenika, D.; Heath, S.; Mamasoula, C.; Cosgrove, C.; Blue, G.; Granados-Riveron, J.; Setchfield, K.; et al. Genome-wide association study of multiple congenital heart disease phenotypes identifies a susceptibility locus for atrial septal defect at chromosome 4p16. Nat. Genet. 2013, 45, 822-824.

34. Jimenez, P.; Saner, K.; Mayhew, B.; Rainey, W.E. GATA6 is expressed in the human adrenal and regulates transcription of genes required for adrenal androgen biosynthesis. Endocrinology 2003, 144, 4285-4288.

35. Kamnasaran, D.; Guha, A. Expression of GATA6 in the human and mouse central nervous system. Brain Res. Dev. Brain Res. 2005, 160, 90-95.

36. Sun-Wada, G.H.; Manabe, S.; Yoshimizu, T.; Yamaguchi, C.; Oka, T.; Wada, Y.; Futai, M. Upstream regions directing heart-specific expression of the GATA6 gene during mouse early development. J. Biochem. 2000, 127, 703-709.

37. Molkentin, J.D.; Antos, C.; Mercer, B.; Taigen, T.; Miano, J.M.; Olson, E.N. Direct activation of a GATA6 cardiac enhancer by $N K X 2-5$ : Evidence for a reinforcing regulatory network of $N K X 2-5$ and GATA transcription factors in the developing heart. Dev. Biol. 2000, 217, 301-309.

38. Fu, B.; Luo, M.; Lakkur, S.; Lucito, R.; Iacobuzio-Donahue, C.A. Frequent genomic copy number gain and over-expression of GATA6 in pancreatic carcinoma. Cancer Biol. Ther. 2008, 7, 1593-1601.

39. Ghatnekar, A.; Chrobak, I.; Reese, C.; Stawski, L.; Seta, F.; Wirrig, E.; Paez-Cortez, J.; Markiewicz, M.; Asano, Y.; Harley, R.; et al. Endothelial GATA6 deficiency promotes pulmonary arterial hypertension. Am. J. Pathol. 2013, 182, 2391-2406.

40. Ho, C.K.M.; Wood, J.R.; Stewart, D.R.; Ewens, K.; Ankener, W.; Wickenheisser, J.; Nelson-Degrave, V.; Zhang, Z.; Legro, R.S.; Dunaif, A.; et al. Increased transcription and increased messenger ribonucleic acid (mRNA) stability contribute to increased GATA6 mRNA abundance in polycystic ovary syndrome theca cells. J. Clin. Endocr. Metab. 2005, 90, 6596-6602. 
41. Kamnasaran, D.; Qian, B.; Hawkins, C.; Stanford, W.L.; Guha, A. GATA6 is an astrocytoma tumor suppressor gene identified by gene trapping of mouse glioma model. Proc. Nat. Acad. Sci. USA 2007, 104, 8053-8058.

42. Vähätalo, R.; Asikainen, T.M.; Karikoski, R.; Kinnula, V.L.; White, C.W.; Andersson, S.; Heikinheimo, M.; Myllärniemi, M. Expression of transcription factor GATA6 in alveolar epithelial cells is linked to neonatal lung disease. Neonatology 2011, 99, 231-240.

43. Bruneau, B.G. Signaling and transcriptional networks in heart development and regeneration. Cold Spring Harb. Perspect. Biol. 2013, 5, a008292.

44. McCulley, D.J.; Black, B.L. Transcription factor pathways and congenital heart disease. Curr. Top. Dev. Biol. 2012, 100, 253-277.

45. Chen, J.; Wang, D.Z. MicroRNAs in cardiovascular development. J. Mol. Cell. Cardiol. 2012, 52, 949-957.

46. Srivastava, D. Making or breaking the heart: from lineage determination to morphogenesis. Cell 2006, 126, 1037-1048.

47. Charron, F.; Paradis, P.; Bronchain, O.; Nemer, G.; Nemer, M. Cooperative interaction between GATA4 and GATA6 regulates myocardial gene expression. Mol. Cell Biol. 1999, 19, 4355-4365.

48. Zhao, R.; Watt, A.J.; Battle, M.A.; Li, J.; Bondow, B.J.; Duncan, S.A. Loss of both GATA4 and GATA6 blocks cardiac myocyte differentiation and results in acardia in mice. Dev. Biol. 2008, 317, 614-619.

49. Maitra, M.; Schluterman, M.K.; Nichols, H.A.; Richardson, J.A.; Lo, C.W.; Srivastava, D.; Garg, V. Interaction of GATA4 and GATA6 with TBX5 is critical for normal cardiac development. Dev. Biol. 2009, 326, 368-377.

50. Lien, C.L.; Wu, C.; Mercer, B.; Webb, R.; Richardson, J.A.; Olson, E.N. Control of early cardiac-specific transcription of NKX2-5 by a GATA-dependent enhancer. Development 1999, 126, $75-84$.

51. Searcy, R.D.; Vincent, E.B.; Liberatore, C.M.; Yutzey, K.E. A GATA-dependent NKX2-5 regulatory element activates early cardiac gene expression in transgenic mice. Development 1998, $125,4461-4470$.

52. Fischer, A.; Klattig, J.; Kneitz, B.; Diez, H.; Maier, M.; Holtmann, B.; Englert, C.; Gessler, M. Hey basic helix-loop-helix transcription factors are repressors of GATA4 and GATA6 and restrict expression of the GATA target gene $A N F$ in fetal hearts. Mol. Cell. Biol. 2005, 25, 8960-8970.

53. Sakata, Y.; Kamei, C.N.; Nakagami, H.; Bronson, R.; Liao, J.K.; Chin, M.T. Ventricular septal defect and cardiomyopathy in mice lacking the transcription factor CHF1/Hey2. Proc. Natl. Acad. Sci. USA 2002, 99, 16197-16202.

54. Van der Bom, T.; Zomer, A.C.; Zwinderman, A.H.; Meijboom, F.J.; Bouma, B.J.; Mulder, B.J. The changing epidemiology of congenital heart disease. Nat. Rev. Cardiol. 2011, 8, 50-60.

55. Verheugt, C.L.; Uiterwaal, C.S.; van der Velde, E.T.; Meijboom, F.J.; Pieper, P.G.; van Dijk, A.P.; Vliegen, H.W.; Grobbee, D.E.; Mulder, B.J. Mortality in adult congenital heart disease. Eur. Heart J. 2010, 31, 1220-1229.

(C) 2014 by the authors; licensee MDPI, Basel, Switzerland. This article is an open access article distributed under the terms and conditions of the Creative Commons Attribution license (http://creativecommons.org/licenses/by/3.0/). 